\title{
Integrating Societal and Scientific Elements into Sustainable and Effective Water Resource Policy Development
}

\author{
J. L. Gutenson ${ }^{1}$, A. N. S. Ernest ${ }^{2 *}$, B. L. Bearden ${ }^{3}$, C. Fuller ${ }^{2}$, and J. Guerrero ${ }^{2}$ \\ ${ }^{I}$ U. S. Army Engineer Research and Development Center, Department of Civil, Construction, and Environmental Engineering, \\ The University of Alabama, Tuscaloosa, AL 35487, United States \\ ${ }^{2}$ Research, Applied Technology, Education and Service, Inc. RATES, P.O. Box 697, Edinburg, TX 78540, United States \\ ${ }^{3}$ Department of Geography, The University of Alabama, Tuscaloosa, AL 35487, United States
}

Received 21 October 2020; revised 23 November 2020; accepted 26 November 2020; published online 31 December 2020

\begin{abstract}
Sustainable water policy is predicated on engaged and representative stakeholders acting on sound and continuously evolving science. Just as stakeholder perspectives are numerous and diverse, so are the scientific disciplines or subject areas that define the availability, impact and use of water. There exists a need for scientists, engineers, and policy makers to better underst and the inextricable network of feedback loops associated with the implementation of the science of water resources management and the policy enabling water resources management. In this article, we propose the Water Resources Integrated Science and Policy Research (WRISPR) concept. WRISPR is a framework to engage stakeholders and policy makers in integrated water policy formation using a singular framework underpinned with cutting edge cyberinfrastructure and modeling tools. We find that WRISPR can be successfully applied by developing a demonstrative cyberinfrastructure framework in two distinct regions of the United States. We propose that WRISPR can be scaled to empower science-driven water policy at multiple spatial and temporal ranges.
\end{abstract}

Keywords: data-driven, decision support systems, DIKW, hydroinformatics, water governance, water policy

\section{Introduction}

Research has long demonstrated how workforce diversity can strengthen an organization's capacity when coupled with effective diversity-management strategies (Richard, 2000; Cunningham, 2009). Advances in computational capabilities and the availability of big data, have created a new plane on which to develop policy (Esty and Rushing, 2007), in such forms as policy analytics (Longo and McNutt, 2018) and data-driven anticipatory governance (Maffei et al., 2020). However, like diversity in organizations and the enabling diversity-management strategies that allow diversity to improve organizational performance, we must determine how to create the capacity within governance that is necessary for us to fully take advantage of these new data-driven policy capabilities (Giest, 2017).

Data driven policy offers both opportunities and challenges for governments to reconceptualize traditional water policy endeavors and take advantage of the growing abundance of water data (Bearden et. al, 2016; Doro et al., 2020). The capabilities of computational hydrology continue to grow in scale (Alfieri et al., 2013; Snow et al., 2016; Tavakoly et al., 2017; Salas et al., 2018) and fidelity (Fatichi et al., 2016), offering expanding data availability with which to propel data-driven water policy.

${ }^{*}$ Corresponding author. Tel.: 956-540-9390.

E-mail address: anernest@ratesresearch.org (A. N. S. Ernest).

ISSN: 2663-6859 print/2663-6867 online

(C) 2020 ISEIS All rights reserved. doi:10.3808/jeil.202000048.
However, the ubiquitous nature of water creates a scenario where many diverse stakeholders and levels of government must collaborate to formulate effective policy. The diversity of perspectives and governance structures that characterize these collaborative groups can create communication challenges and disharmony when developing and executing sound water policy (Howarth and Monasterolo, 2016; Daher et al., 2020; Makaya et al., 2020).

Nowhere are the challenges and opportunities of datadriven water policy more evident than in the state of Alabama where the lack of an integrated, comprehensive, water resources management plan led to the creation of the Alabama Water Agencies Working Group (AWAWG) in 2012 (disbanded 2017). AWAWG brought together statewide stake-holders and state agencies in an effort to build the state's first comprehensive water resources management plan in the face of mounting social, economic, and environmental pressures. From its inception, AWAWG's charge was to produce comprehensive water resource management policy that was based on sound science and integrated stakeholder and agency needs (AWAWG, 2013). Concurrent engagement of disparate stakeholder groups and state agencies posed significant obstacles to developing scientifically sound state water management plans.

The state of Alabama is not in isolation with respect to the need to balance sound science and multiple human perspectives to develop sustained and effective water resource policy. At a more local geographic scale, the Lower Rio Grande Valley 
(LRGV) in south Texas must balance social, economic, and environmental needs in managing stormwater and the associated infrastructure. Founded in the 1990s to support local governments in meeting Phase 2 stormwater regulations pending at that time, the LRGV Texas Pollutant Discharge Elimination System (TPDES) Stormwater Taskforce (SWTF) has evolved to balance the diverse needs of its now 30+ members and stakeholder groups. Much like AWAWG, the SWTF seeks to harmonize science with human needs to achieve the most effective policy solutions for the region.

Sustainable water policy is predicated on engaged and representative stakeholders (Lemos and Morehouse, 2005) acting on sound and continuously evolving science (Jury and Vaux, 2005). Just as stakeholder perspectives are numerous and diverse, so are the scientific disciplines or subject areas that define the availability, impact and use of water. While the classical hydrologist "studies water", the hydrologic cycle is heavily influenced by meteorology, land use patterns and civil infrastructure improvements. Sectors such as agriculture, industry and energy production both depend upon, and can influence the water cycle. Arguably, the purpose of effective policy is to promote a social or environmental good, both of which can often be measured in economic terms. Sustainable water policy development is therefore at the nexus of these myriad of disciplines and perspectives (Figure 1).

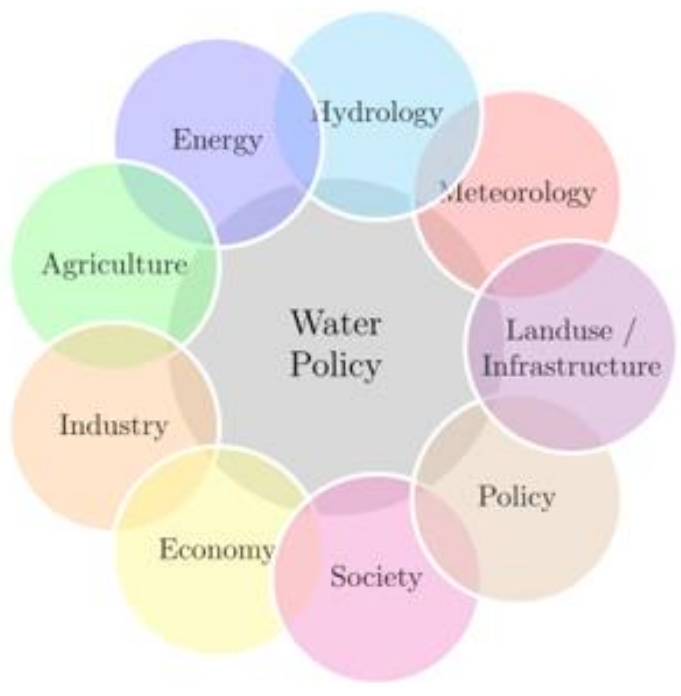

Figure 1. Water policy process interactions for resiliency and economic growth.

The old Indian fable of the Six Blind Men and the Elephant (Figure 2) is certainly apropos to the development of water policy. Each stakeholder views the water "elephant" from their own parochial perspective, and argues that theirs is reality. Nowhere was this more evident than in many of the Alabama Water Agencies Working Group (AWAWG) Focus Area Panels in 2017. The elephant metaphor can be extended to illustrate the traditionally stove-piped process of translation of scientific discovery into stakeholder knowledge. Each blind man investigates in exquisite detail the aspect of the "elephant" that they are directly confronted with - the trunk, the tusk, the ear, the side, the foot and the tail. Their failure is twofold - first, in their inability to comprehend that all perspectives are possible, and second, more procedurally, the laser-focus each has on only what is directly in front of them. Perhaps, had they shared their initial impressions with each other, they may have been more willing to shift their positions slightly as they continued their inspections and, as a result, develop a shared, more inclusive and comprehensive picture.

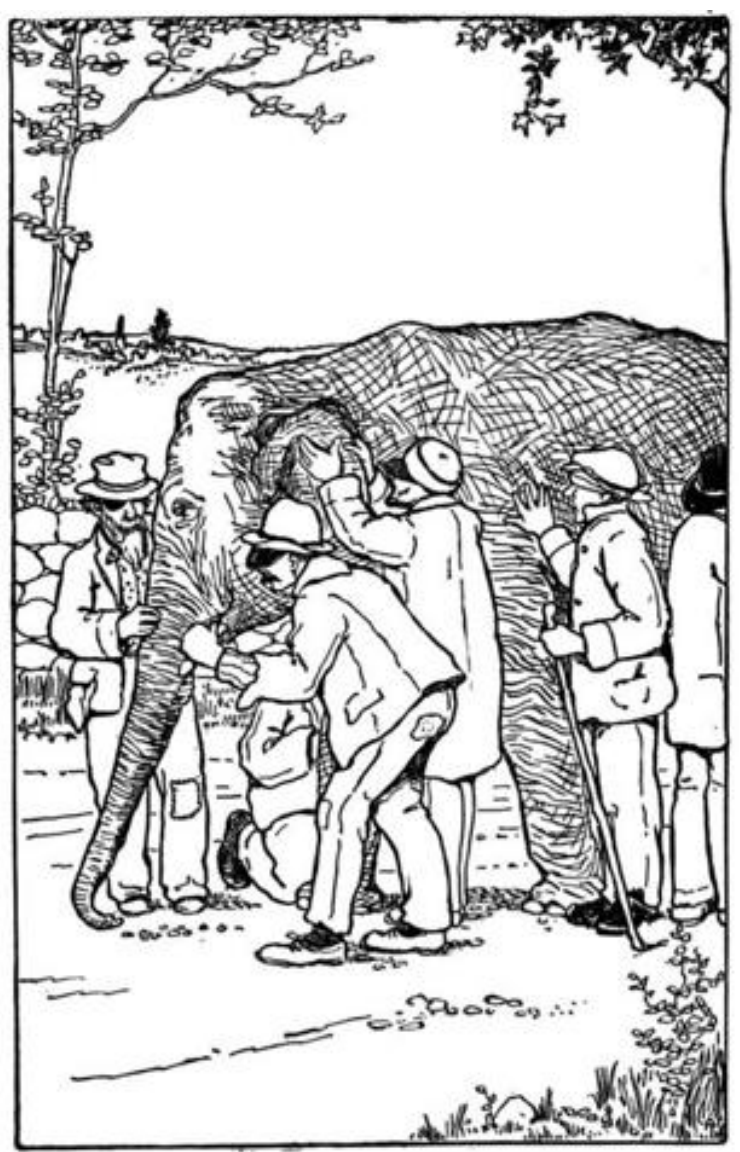

Figure 2. The fable of the six blind men and the elephant. (https://commons.wikimedia.org/wiki/File:Blind_men_and_el ephant.jpg)

In rough counterpoint to the elephant fable, is the concept of a Common Operating Picture (COP) adopted by several agencies including the Department of Homeland Security (DHS) and the National Oceanic and Atmospheric Agency's (NOAA) National Weather Service (NWS). COP is a Situational Awareness (SA) capability designed to ensure that all participating stakeholder and/or decision makers possess the full suite of information necessary for the job at hand. Extending the elephant fable further, implementation of a COP would ensure that each of the six blind men shared their discoveries with each other in real time, and, most importantly, in a language that each can understand.

Occam's Razor (Domingos, 1999), also embodied in the 
K.I.S.S. (Keep It Simple, Sweetheart) principle, is a philosophic principle that promotes parsimony in the adoption of assumptions in decision making. The assertion that "all models are wrong, but some are useful" (Box, 1976), combined with Occam's Razor, provides some insights into potentially more effective decision-making processes that would facilitate the rapid determination that an elephant is a large animal with a trunk, tusks, flappy ears, big feet and a tail.

Access to knowledge, and the ability to analyze it in one's own language to develop a shared perspective is therefore key to decision making. Cash et al. (2003) identify three core functions necessary to breakdown parochial stovepipes - Communication, Translation and Mediation.

In this research, we hypothesize that sustainable water policy development can be achieved by facilitating communication, translation, and mediation amongst the disciplines and perspectives involved in developing water policy and unpinning this facilitation with appropriate scientific guidance. Focusing on the past experiences of AWAWG and the future needs of the SWTF, we provide a demonstration of the WRISPR concept. We describe the WRISPR concept and use this concept to devise a demonstration of the tools and cyberinfrastructure necessary to prove the WRISPR concept.

\section{Methods}

WRISPR is a concept to address the need for integrated and adaptive water resource management structures. Understanding that this underlying procedural need is exacerbated by the ubiquity of "water data", and that in the context of resource management, water data transcends hydrologic parameters to include socio-economic and socio-political drivers. While Mathematics might be the language of the universe, parochial perspectives significantly influence the interpretation of data. To promote a more sustainable, open, engaged and adaptive governance style, disciplinary and parochial perspectives must be accounted for to ensure effective Communication between the diverse sectors engaged in the decision process. This can be ensured through the provision of a COP that relies on coherent and common knowledge, Translated into the appropriate parochial and/or disciplinary perspectives. Engaged decision-, or policy-, making is then reliant on the process of relating, rather than educating, to diverse perspectives through the process of Mediation.

WRISPR promotes Communication, Translation and Mediation through core reliance on the Data, Information, Knowledge and Wisdom (DIKW) pyramid (Figure 3). "Typically, information is defined in terms of data, knowledge in terms of information, and wisdom in terms of knowledge" (Rowley, 2007). The DIKW pyramid represents an evolution of information from the rawest form (data) to the most refined (wisdom). An added dimension to this pyramid is perspective, which in its most simplistic form can be seen as a selective sequence of processing - e.g., the synthesis of raw data into information can be executed in such a way so as to address the unique perspectives of a particular discipline or parochial sec- tor. The progressive application of scientific principles, ranging in complexity from simple analytics to intricate mechanistic models, and encompassing disciplines from physics to the social sciences, promotes the achievement of "wisdom".

In the context of water resource management, attaining "wisdom" entails an integration of the diverse perspectives of the spectrum of stakeholders with core scientific principles into a coherent policy framework that results in a public good (Figure 4).

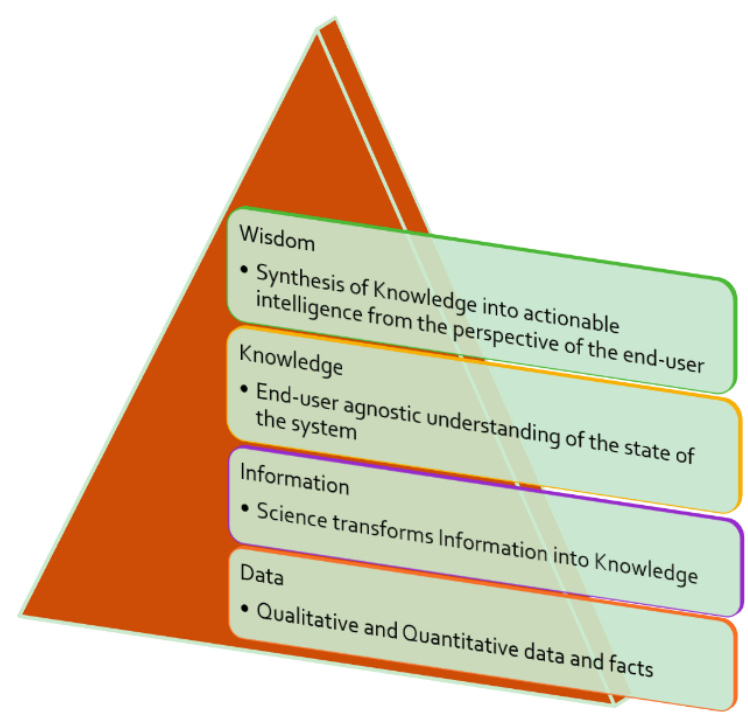

Figure 3. The DIKW pyramid.

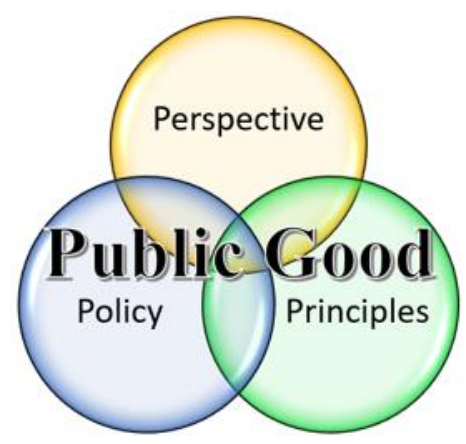

Figure 4. Achieving public good through integration of scientific principles, diverse.

\section{Perspectives and Policy Development}

WRISPR consists of the Cyberinfrastructure to provide Access to Data, along with a core suite of Analytics tools (Figure 5). The Information layer includes a Toolbox of more intricate empirical and mechanistic Models, along with an integrated suite of Visualization tools to allow the ready discourse between diverse sectors and Perspectives to promote Engagement of researchers and stakeholders at the Knowledge layer. The core end-point for WRISPR is the development and Implementation of sustainable water management policy structures that achieve a Public Good - i.e., Wisdom. 


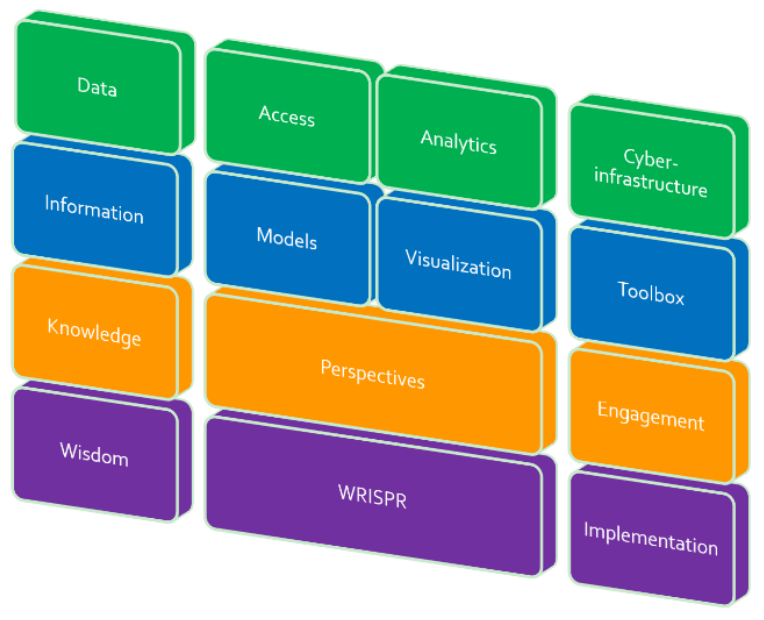

Figure 5. WRISPR conceptual formulation.

\section{Results and Discussion}

\subsection{Results}

The cyberinfrastructure presented in this section provides the capacity with which to deploy the WRISPR concept in two cases in Alabama and Texas. We detail how the infrastructure encapsulates the DIKW pyramid to tackle water resource policy needs.

\subsubsection{Data}

Two separate cyberinfrastructures were developed to propel WRISPR initiatives in Alabama and Texas. Both cyberinfrastructures provided the data portion of the DIKW pyramid. In Alabama, foremost among these efforts was the pursuit and successful award of a National Science Foundation (NSF) Campus Cyberinfrastructure grant to deploy The University of Alabama (UA) SciNET (The University of Alabama, 2020). UA SciNET is a campus-wide high-speed data network that effecttively removes bandwidth bottlenecks, permitting retrieval, analysis and visualization of large datasets between physically separate, compute-intensive sites, including the National Water Center (NWC) which sits on the UA campus. In conjunction with this effort, and to afford researchers with ready access to large datasets, specifically those produced by the NWC, a largescale data storage and retrieval service was developed and deployed through a partnership between the UA Office of Research and Economic Development (ORED) and the Office of Information Technology (OIT) as the UA Research Data Services (UARDS). To ensure accessibility and reliability of data resources from disparate locations across the continental US, federated data services were deployed using the Integrated RuleOriented Data System (iRODS) (iRODS Consortium, 2020). To facilitate data management and retrieval, a suite of web services was deployed via UARDS. The core service is a data archival server (CKAN, 2020) that promotes rapid deposit of multiple forms of data. Core to data archival is the provision of flexibility to rapidly assimilate unstructured data and mechanisms for integrating diverse data structures, sources and meta- data information. In addition to data archival, map services (GeoServer, 2020) enable geolocation of data and production of Open Geospatial Consortium (OGC) compliant geospatial data services for integration with disparate COPs. UARDS was deployed and linked to the UA High Performance Computing cluster (UAHPC) in preparation for 2016 NWC/YIP Summer Institute. To feed the UARDS prior to the production release of the NWM, the NWC, Deltares and UA collaborated on a standalone deployment of the Deltares Flood Early Warning System (FEWS), customized for National Weather Service (NWS) Advanced Hydrologic Prediction Service (AHPS) data intake that was then made available as a public WaterML2 data service.

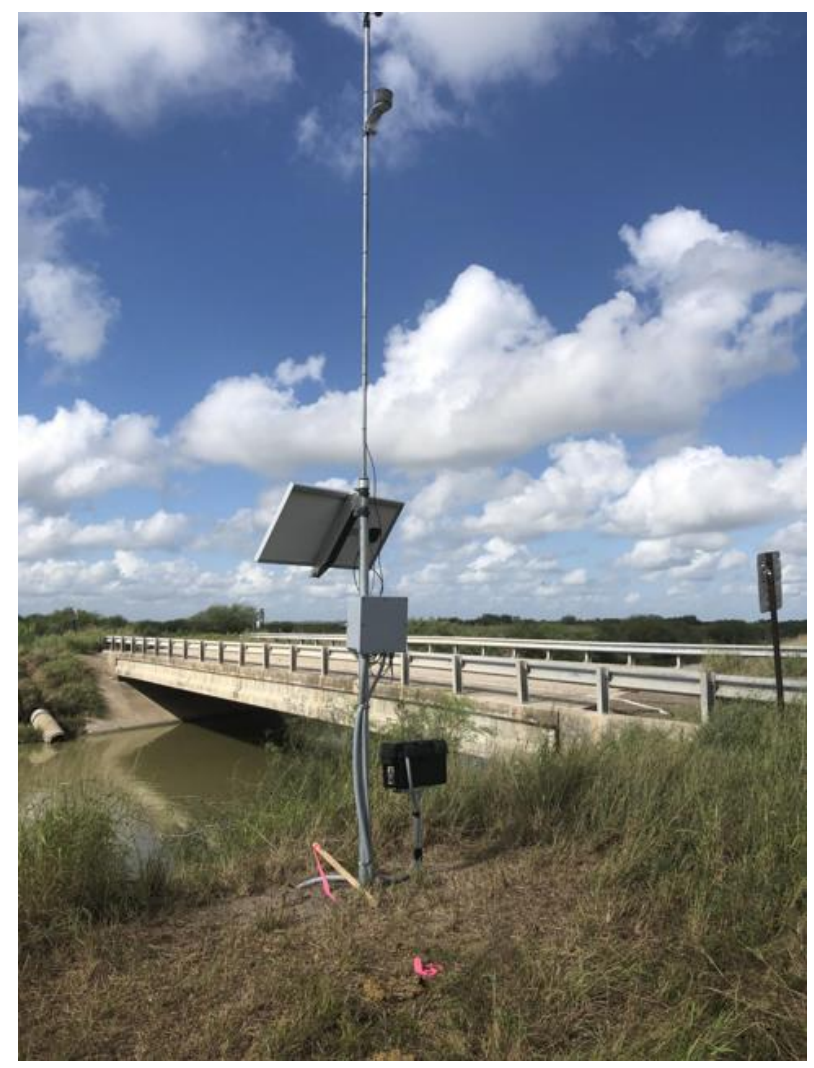

Figure 6. Real time hydrologic system installed in South Texas.

The River and Estuary Observation Network (REON), first deployed in New York State in 2010 then extended to Texas in 2019, represents a culmination of professional investments to "democratize of water intelligence", whereby continuous hydrologic and water quality data necessary to characterize " $99 \%$ of environmental impacts that occur in 1\% of the time" was made available to the masses. In counterpoint to UARDS which promotes data access to academic researchers, REON is focused on promoting raw data access to local governmental entities, non-governmental organizations, and private citizens. REON is composed of over 70 Real Time Hydrologic Systems (RTHS) which were designed, developed and deployed from the ground up to be low cost, highly reliable and highly accurate. REON and RTHS formed the foundation of the non-profit research, education and capacity development corporation Re- 
search, Applied Technology, Education and Service, Inc. (RATES) established in 2005. RTHS stations (Figure 6) include inhouse designed components including a data collection and telemetry base station and in-situ sensors to measure stream stage height, water temperature, and meteorological parameters.

\subsubsection{Information}

With a core data-cyberinfrastructure in-place between the partnering entities, the next tier of DIKW investment is development of the Information Toolbox. Parallel client-side analytic tools for water resource management can be deployed using cloud connectivity. In Alabama, Operational Analysis and Simulation of Integrated Systems (OASIS) (Hazen and Sawyer, 2019), Water Evaluation and Planning (WEAP) (Stockhom Environmental Institute, 2020), and RiverWare (University of Colorado - Boulder, 2020) are possible toolkits that can ingest the data supplied by the WRISPR cyberinfrastructure. These production-ready tools provide water resource allocation and management decision support capacity, along with core functionality that permits engagement of stakeholders in scenario evaluation processes. Water Wizard (Gutenson et al., 2018) is a suite of expert system tools that embrace the WRISPR philosophy and are developed specifically to perform analytical and decision support functions on raw hydrologic and water quality data. Many of these tools integrate off-the-shelf tool-chains, such as the Python Knowledge Engine (PyKE) (Sourceforge, 2009), to rapidly integrate Subject Matter Expertise into applications and web platforms such as GeoNode (GeoNode, 2012) for rapid deployment of geospatially augmented web content. Though differing from tools proposed for use in Alabama, the Water Wizard suite of tools, deployed within REON in Northern New York and South Texas, will again rely upon the data feeds within the WRISPR cyberinfrastructure.

\subsubsection{Knowledge}

Core to the WRISPR philosophy is the adoption of "relating" rather than "educating". As a result, the processes of knowledge development must be tightly integrated with engagement between diverse sectors and perspectives rather than relying on infrequent dissemination cycles. A conceptual example of this philosophy is reliance on daily (or on-demand) "blogs" for knowledge dissemination over publication in aptlynamed "periodicals". NSF promotion of "cybercollaboratories" to promote multi-disciplinary discourse is indicative of this trend. Indeed, deployment of a WRISPR cybercollaboratory is possible where a cyberinfrastructure consolidates data and delivers translated information via a series of web services and portals in formats that are universally comprehensible by disparate stakeholders. To serve as a cybercollaboratory during the 2016 NWC-Young Innovators Program-Summer Institute (NWC-YIP-SI), an instance of Tethys Platform was deployed and fed by the UARDS. Tethys is a water resources web application framework developed by Brigham Young University (BYU) that delivers water resources data and information in formats that promote the collection and visualization of data and information that promotes actionable intelligence (i.e., knowledge) for decision makers (Nelson et al., 2019). In Texas, REON.cc now serves as a cybercollaboratory, leveraging the real-time data network afforded by the $70+$ RTHS stations through a GIS enabled web platform, serving as a cloud platform for engaging stakeholders with an interest in the Data and Information provided therein.

\subsubsection{Wisdom}

The final tier of the DIKW pyramid is wisdom, which promotes the development, adoption and implementation of sustainable water management policy. Parallel to the multi-state deployment of the WRISPR framework has been the execution of projects that support the adaptive and sustainable policy implementation goals. Core to this approach is the formation of multijurisdictional coordination networks such as the SWTF, and the facilitation of knowledge enabled collaborative decision making.

\subsection{Discussion}

\subsubsection{WRISPR Implementation}

The SWTF was established in 1998 at Texas A\&M University - Kingsville (part of a land-grant system) to leverage its educational roots, regional scope, and relationship to the statewide extension service. In 2016, following the establishment of the University of Texas - Rio Grande Valley (UTRGV), the SWTF moved to UTRGV and experienced explosive growth. However, UTRGV core missions of teaching and research are not aligned with the SWTF mission that is more akin to a state supported extension service. In 2019, the SWTF merged with Research Applied Technology, Education Services, Inc. (RATES, Inc.), a nonprofit corporation that is administratively organized to support stakeholder outreach and engagement activities.

Following the SWTF merger with RATES and after 20 years of engaging local governments in multi-jurisdictional environmental and water resource decision making, the efforts of the SWTF culminated in the establishment of the Regional Water Resource Advisory Committee (RWRAC), a standing committee of the Lower Rio Grande Valley Development Council (LRGVDC), a council of governments serving a three-county region in the southernmost tip of Texas. A key outcome of the RWRAC has been the realization by elected officials that make up its membership that regional water resource management and inter-jurisdictional policy making must be grounded in sound science. This has resulted in the establishment of the LRGV Watershed Coordinator, a shared technical resource jointly funded by the three counties (Cameron, Hidalgo and Willacy) and RATES, housed at the LRGVDC. By creating this regional technical resource, the entire LRGV region has been able to increase its focus on hydrologic and environmental solutions with a regional rather than parochial perspective. Elected officials and decision makers have rapidly realized the value of understanding the science behind regional water resource issues as a critical first step in making effective collaborative decisions. This has resulted in the LRGVDC pursuing a multi-million-dollar initiative to expand the understanding of the hydrology and hydraulics of the region with the Watershed 
Coordinator playing the critical role of informing and educating the decision makers with non-parochial knowledge.

Trust is the single most important element in the success of the SWTF model. Trust is created by ensuring that SWTF mission is apolitical and non-jurisdictional. Regular, outcomes based, workshops encourage knowledge-based dialogue between the individual citizens, special interest groups and local decision makers. These events facilitate establishment of coordination bodies, comprised of regional decision makers such as the RWRAC, with capacities to increase state and federal investments in the region.

The success that the SWTF has enjoyed since the 2019 transition to RATES posits the notion that WRISPR can achieve more in Texas if implemented in a manner similar to the current SWTF. This would entail transitioning from WRISPR's academic administration toward an extension service administration whose mission is to provide regional constituencies with the knowledge and tools required to address their respective water resource issues. Personal interactions between extension service agents and their constituents are necessary to convey the needs of both parties and develop a level of trust necessary to implement effective, scientifically based management decisions. In many ways the LRGV Watershed Coordinator, serving as an unbiased liaison, is the physical embodiment of the WRISPR model whereby the Watershed coordinator brokers trust among water resource pundits, governmental agencies, conservation groups, and affected residents.

\subsubsection{IWRSS/NWC Linkage}

Efforts are ongoing within the U. S. Federal government to establish more integrated water science and policy amongst the Federal agencies who each have a component of their mission encompassing the gamut of water resource planning and management activities. Four of the Federal agencies, the Federal Emergency Management Agency (FEMA), National Weather Service (NWS), U. S. Army Corps of Engineers (USACE), and U. S. Geological Survey (USGS), established the Integrated Water Resources Science and Services (IWRSS) consortium. IWRSS is intended to create a unified COP amongst the IWRSS agencies (Cline, 2009). To facilitate the growth of the IWRSS COP, the NWC was constructed on the campus of UA. The IWRSS and NWC are intended to become a hub of Federal integrated water resource science and decision making (IWRSS, 2012).

Each IWRSS agency brings into the consortium a unique set of perspectives, organic mission requirements and objecttives, technical capacities, stakeholders, budgets, and workforce composition. While each agency is accountable for their individual mission, the underlying data and information necessary to empower the agency in meeting their organic mission are composed of the same basic components, such as rainfall forecasts, streamflow, and flood inundation maps. However, these data, information, and the underlying infrastructure do not reside within a unified framework, further complicating already divergent vantage points.

Efforts are ongoing to unite data and information amongst the IWRSS agencies. For example, an ongoing national flood inundation mapping effort seeks to unite all IWRSS flood inundation mapping products into a unified product for a given flood event (IWRSS, 2013; IWRSS, 2015). However, what remains necessary is a mechanism to more holistically unite policy decisions made by the agencies and empower these decisions with the best available science. Such a mechanism can be empowered by the data and information that each agency produces, promote a collaborative culture amongst the agencies, and clarify where capability gaps exist amongst the agencies.

The WRISPR concept can proactively empower collaborative policy within the IWRSS consortium by uniting data, models, and infrastructure and relating these to each agency in a way that speaks to the agency's need to meet their organic mission. Through the use of underlying data services that provision and shape the data into the appropriate perspective.

\subsubsection{USACE Project Justification Implications \& Applications}

The Economic and Environmental Principles and Guidelines for Water and Related Land Resources Implementation (Principles and Guidelines) serves as the formative guidance document for evaluating major Federal water resource projects across all major Federal water resource development agencies (U. S. Water Resources Council, 1983). Principles and Guidelines lays out four accounts by which the major Federal water agencies may evaluate and display the effects of alternative project plans. The National Economic Development (NED) account displays changes in economic value of national output that result from the implementation of a project. The Environmental Quality (EQ) account registers the non-monetary impacts that the project has on natural and cultural resources. The Regional Economic Development (RED) account compiles the changes that each plan enacts upon regional economic activity, and Other Social Effects (OSE) account registers other impacts the project may have on relevant stakeholders that the NED, EQ, and RED accounts do not encompass.

For USACE, the implementation of Principles and Guidelines is described in the USACE circular No. 1105-2-409 (EC 409). EC 409 states that, in deciding between project alternatives, USACE should select any alternative deemed to have positive net beneficial effects. Positive net benefits should be determined by analyzing the project through at least two of the four of the Principles and Guidelines evaluation accounts. Traditionally, there has been an over reliance on the use of the NED account due to the established tools and procedures available to evaluate these accounts. This over reliance on NED can limit the scope of problems the proposed project will address and limit understanding of project alternative impacts (Durden and Wegner-Johnson, 2013).

The incorporation of non-NED accounts into the USACE project planning process can be facilitated by WRISPR. The fact that the other three accounts have been devised indicates that the current accounting paradigm is not a product of unavailable data or information that could empower the use of non-NED accounts in the planning process. The current accounting paradigm is more attributable to a lack of an ability to shape 
the data and information into an appropriate perspective that facilitates the growth of knowledge and wisdom among different practitioner backgrounds. There are well known environmental, economic, and societal phenomena (data and information) that are not fully accounted for by the status quo planning process. For example, flooding can have documented and appreciable negative impacts to psychological health (French et al., 2019), physiological health (Saulnier et al., 2017), and life satisfaction (Leeching and Raschky, 2008) that last beyond a flood event. In addition, unconventional avenues of support, such as social capital, can work to simultaneously mitigate and enhance the adverse impacts of floods (Babcicky and Seebauer, 2017). Many of these impacts and overlooked non-structural alternatives offer potential to provide more pragmatic flood risk management strategies. However, the process of translating this information into meaningful policy formation, in this case in the formation and choice of project alternatives, has proven troublesome. What seems to be lacking is a cohesive transfer of relevant information between the disciplines. WRISPR offers the capability to provide relevance to engineers, social scientists, and public health officials by empowering the sharing of objective data and information, based upon the user's paradigm.

\section{Conclusions}

We propose WRISPR as a novel framework for enabling integration of societal and scientific elements for effective water resource policy development. WRISPR relies upon the DIKW pyramid to assist in the synthesis of raw data into information that can be executed in a manner to address the unique perspectives of a particular discipline or parochial sector.

Leveraging the WRISPR concept, we detail two instances of how a number of cutting-edge cyberinfrastructure tools can be applied to address informed decision-making needs. Integration of these tools will facilitate application of the WRISPR concept by being directly based upon the DIKW pyramid. The cyberinfrastructure serves to illustrate how the policy and stakeholder engagement needs of spatially distinct and independent groups, namely the AWAWG (from 2013 2017) and the SWTF, can be addressed by a singular set of integrated cyberinfrastructure and computational tools. The SWTF has seen a significant transformation in its effectiveness following the transition to a public-private partnership. The role of Watershed Coordination is established as an unbiased mediator of the partnership and brokers trust amongst the affiliated organizations. Because trust is so pivotal in the adoption of new technology, we assert that WRISPR's implementation in the LGRV will benefit from the relationships formed by the Watershed Coordinator. The WRISPR concept can: be extended to address Federal water resource issues; be applied to empower collaborative policy formation amongst the IWRSS consortium by uniting data, models, and infrastructure and relating these to each agency in a way that speaks to the agency's need to meet their organic mission; and help USACE provide relevance to the numerous disciplines involved in the project justification process through translation of existing data and information into meaningful policy outcomes.

Acknowledgments. This work was partially supported by the National Science Foundation under award \#1541462 entitled "CC*DNI Networking Infrastructure - University of Alabama SciNet". The authors are grateful for the thoughtful comments from all reviewers.

\section{References}

Alabama Water Agencies Working Group. (2013). Mapping the future of Alabama water resources management: Policy options and recommendations. Alabama Department of Economic and Community Affairs. Retrieved from http://adeca.alabama.gov/Divisions/ owr/awawg/Documents/AWAWG-Report-FINAL-2-Side-Print. pdf.

Alfieri, L., Burek, P., Dutra, E., Krzeminski, B., Muraro, D., Thielen, J., and Pappenberger, F. (2013). GloFAS-global ensemble streamflow forecasting and flood early warning. Hydrology and Earth System Sciences, 17(3), 1161-1175. https://doi:10.5194/hess-17-11 61-2013

Babcicky, P., and Seebauer, S. (2017). The two faces of social capital in private flood mitigation: opposing effects on risk perception, selfefficacy and coping capacity. Journal of Risk Research, 20(8), 10171037. http://doi:10.1080/13669877.2016.1147489

Bearden, B.L., Ernest, A., Clark, E. and Zhu, L. (2016). Data-Driven Policy Making, The Wave Water Policy Column, Alabama Water Environment Association, v. 37, no. 1 (Spring 2016) p. 21-28.

Box, G.E. (1976). Science and Statistics. Journal of the American Statistical Association, 71, 791-799. https://doi:10.1080/01621459. 1976.10480949

Cash, D.W., Clark, W.C., Alcock, F., Dickson, N.M., Eckley, N., Guston, D.H., Jager, J., Mitchell, R.B. (2003). Knowledge systems for sustainable development. Proceedings of the National Academy of Sciences, 100, 8086-8091. https://doi:10.1073/pnas.1231332100

CKAN. (2020). Home. https://ckan.org/ (accessed November 1, 2020)

Cline, D. (2009). Integrated Water Resources Science and Services (IWRSS): An Integrated and Adaptive Roadmap for Operational Implementation, Report No. IWRSS-2009-03-02.

Cunningham, G.B. (2009). The moderating effect of diversity strategy on the relationship between racial diversity and organizational performance. Journal of Applied Social Psychology, 39(6), 1445-1460. http://doi:0.1111/j.1559-1816.2009.00490.x

Daher, B., Hannibal, B., Mohtar, R.H., and Portney, K. (2020). Toward understanding the convergence of researcher and stakeholder perspectives related to water-energy-food (WEF) challenges: The case of San Antonio, Texas. Environmental Science and Policy, 104 (April 2019), 20-35. http://doi:10.1016/j.envsci.2019.10.020

Doro, K.O., Ehosioke, S., and Aizebeokhai, A.P. (2020). Sustainable soil and water resources management in Nigeria: The need for a data-driven policy approach. Sustainability (Switzerland), 12(10), 1-21. http://doi:10.3390/su12104204

Durden, S.E., and Wegner-Johnson, M. (2013). Other Social Effects: A Primer, Report No. 2013-R-02.

Esty, D., and Rushing, R. (2007). The promise of data-driven policymaking. Issues in Science and Technology, 23(4), 67-72. https:// www.jstor.org/stable/43314516.

Fatichi, S., Vivoni, E.R., Ogden, F.L., Ivanov, V.Y., Mirus, B., Gochis, D., Downer, C.W., Camporese, M., Davison, J.H., Ebel, B., Jones, N., Kim, J., Mascaro, G., Niswonger, R., Restrepo, P., Rigon, R., Shen, C., Sulis, M., and Tarboton, D. (2016). An overview of current applications, challenges, and future trends in distributed processbased models in hydrology. Journal of Hydrology, 537, 45-60. http: //doi:10.1016/j.jhydrol.2016.03.026

French, C.E., Waite, T.D., Armstrong, B., Rubin, G.J., Beck, C.R., and Oliver, I. (2019). Impact of repeat flooding on mental health and health-related quality of life: a cross-sectional analysis of the English 
National Study of Flooding and Health. BMJ open, 9(11). http:// doi:10.1136/bmjopen-2019-031562

GeoNode. (2012). GeoNode. http://geonode.org/ (accessed November $7,2020)$

Geoserver. (2020). Home. http://geoserver.org/ (accessed November 1, 2020)

Giest, S. (2017). Big data for policymaking: fad or fasttrack? Policy Sciences, 50(3), 367-382. http://doi:10.1007/s11077-017-9293-1

Gutenson, J.L., Ernest, A.N.S., Oubeidillah, A. A., Zhu, L., Zhang, X., and Sadeghi, S.T. (2018). Rapid flood damage prediction and forecasting using public domain cadastral and address point data with fuzzy logic algorithms. JAWRA Journal of the American Water Resources Association, 54(1), 104-123. https://doi.org/10.1111/17521688.12556

Hazen and Sawyer. (2019). HydroLogics Staff Join Hazen Water Resources Practice. https://www.hazenandsawyer.com/news/hazenexpands-water-resources-practice/ (accessed November 1, 2020)

Howarth, C., and Monasterolo, I. (2016). Understanding barriers to decision making in the UK energy-food-water nexus: The added value of interdisciplinary approaches. Environmental Science and Policy, 61, 53-60. http://doi:10.1016/j.envsci.2016.03.014

Integrated Water Resources Sciences and Services (IWRSS). (2012). Integrated Water Resources Science and Services (IWRSS): Summit to Sea.

Integrated Water Resources Sciences and Services (IWRSS). (2013). Requirements for the National Flood Inundation Mapping Services.

Integrated Water Resources Sciences and Services (IWRSS). (2015). Design for the National Flood Inundation Mapping Services.

iRODS Consortium. (2020). Home. https://irods.org/ (accessed November 1, 2020)

Jury, W.A., and Vaux, H. (2005). The role of science in solving the world's emerging water problems. Proceedings of the National Academy of Sciences, 102, 15715-15720. http://doi:10.1073/pnas.050 6467102

Lemos, M.C., and Morehouse, B.J. (2005). The co-production of science and policy in integrated climate assessments. Global Environmental Change, 15, 57-68. http://doi:10.1016/j.gloenvcha.2004. 09.004

Longo, J., and McNutt, K. (2018). From policy analysis to policy analytics. Policy Analysis in Canada, 367-389.

Luechinger, S., and Raschky, P.A. (2009). Valuing flood disasters using the life satisfaction approach. Journal of Public Economics, 93(3-4), 620-633. http://doi:10.1016/j.jpubeco.2008.10.003

Maffei, S., Leoni, F., and Villari, B. (2020). Data-driven anticipatory governance. Emerging scenarios in data for policy practices. Policy Design and Practice, 3(2), 123-134. http://doi:10.1080/25741292. 2020.1763896

Makaya, E., Rohse, M., Day, R., Vogel, C., Mehta, L., McEwen, L., Rangecroft, S., and Van Loon, A.F. (2020). Water governance challenges in rural South Africa: Exploring institutional coordination in drought management. Water Policy, 22(4), 519-540. http://doi:10. 2166/wp.2020.234
Nelson, E.J., Pulla, S.T., Matin, M.A., Shakya, K., Jones, N., Ames, D.P., Ellenburg, W.L., Markert, K.N., David, C.H., Zaitchik, B.F., Gatlin, P., and Hales, R. (2019). Enabling stakeholder decisionmaking with earth observation and modeling data using Tethys platform. Frontiers in Environmental Science, 7(October), 1-15. http:// doi: $10.3389 /$ fenvs. 2019.00148

Richard, O.C. (2000). Racial diversity, business strategy, and firm performance: A resource-based view. Academy of Management Journal, 43(2), 164-177. http://doi:10.2307/1556374

Roux, D., Rogers, K., Biggs, H., Ashton, P., and Sergeant, A. (2006). Bridging the science-management divide: moving from unidirectional knowledge transfer to knowledge interfacing and sharing. Ecology and Society, 11. http://doi:10.5751/ES-01643-110104

Rowley, J. (2007). The wisdom hierarchy: representations of the DIKW hierarchy. Journal of Information Science, 33, 163-180. http: //doi:10.1177/0165551506070706

Salas, F.R., Somos-Valenzuela, M.A., Dugger, A., Maidment, D.R., Gochis, D.J., David, C.H., Yu, W., Ding, D., Clark, E.P., and Noman, N. (2018). Towards real-time continental scale streamflow simulation in continuous and discrete space. Journal of the American Water Resources Association, 54(1), 7-27. http://doi:10.1111/17521688.12586

Saulnier, D.D., Ribacke, K.B., and von Schreeb, J. (2017). No calm after the storm: a systematic review of human health following flood and storm disasters. Prehospital and disaster medicine, 32(5), 568579. http://doi:10.1017/S1049023X17006574

Snow, A.D., Christensen, S.D., Swain, N.R., Nelson, E.J., Ames, D.P., Jones, N.L., Ding, D., Noman, N., David, C.H., and Pappenberger, F. (2016). A high-resolution national-scale hydrologic forecast system from a global ensemble land surface model. Journal of the American Water Resources Association (JAWRA), 52(4). http://doi: $10.1111 / 1752-1688.12434$

Sourceforge. (2009). Python Knowledge Engine (PyKE). http://pyke. sourceforge.net/ (accessed November 1, 2020)

Stockholm Environmental Institute. (2020). Water Evaluation and Planning (WEAP). https://www.weap21.org/ (accessed November 1, 2020)

Tavakoly, A.A., Snow, A.D., David, C.H., Follum, M.L., Maidment, D.R., and Yang, Z.L. (2016). Continental-Scale river flow modeling of the mississippi river basin using high-resolution NHD plus dataset. JAWRA Journal of the American Water Resources Association, 53(2), 258-279. http://doi:10.1111/1752-1688.12456

The University of Alabama. (2020). The University of Alabama Reveals SciNet. https://oit.ua.edu/service/scinet/ (accessed November 8,2020 )

University of Colorado - Boulder. (2020). RiverWare. https://www. colorado.edu/cadswes/creative-works/riverware

U. S. Army Corps of Engineers (USACE). (2005). Planning in a Collaborative Environment, Circular No. 1105-2-409.

U. S. Water Resources Council. (1983). Economic and Environmental Principles and Guidelines for Water and Related Land Resources Implementation Studies. Water Resources Council. 